\title{
Study of Nanostructured Polymeric Composites Used for Organic Light Emitting Diodes and Organic Solar Cells
}

\author{
Nguyen Nang Dinh,, ${ }^{1}$ Do Ngoc Chung, ${ }^{1}$ Tran Thi Thao, ${ }^{1}$ and David Hui ${ }^{2}$ \\ ${ }^{1}$ University of Engineering and Technology, Vietnam National University, 144 Xuan Thuy, Cau Giay, Hanoi 10000, Vietnam \\ ${ }^{2}$ Department of Mechanical Engineering, The University of New Orleans, New Orleans, LA 70148, USA
}

Correspondence should be addressed to Nguyen Nang Dinh, dinhnn@vnu.edu.vn

Received 17 July 2012; Accepted 10 September 2012

Academic Editor: Marinella Striccoli

Copyright (C) 2012 Nguyen Nang Dinh et al. This is an open access article distributed under the Creative Commons Attribution License, which permits unrestricted use, distribution, and reproduction in any medium, provided the original work is properly cited.

\begin{abstract}
Polymeric nanocomposite films from PEDOT and MEH-PPV embedded with surface modified $\mathrm{TiO}_{2}$ nanoparticles for the hole transport layer and emission layer were prepared, respectively, for organic emitting diodes (OLEDs). The composite of MEH$\mathrm{PPV}+\mathrm{nc}-\mathrm{TiO}_{2}$ was used for organic solar cells (OSCs). The characterization of these nanocomposites and devices showed that electrical ( $I-V$ characteristics) and spectroscopic (photoluminescent) properties of conjugate polymers were enhanced by the incorporation of $\mathrm{nc}^{-} \mathrm{TiO}_{2}$ in the polymers. The organic light emitting diodes made from the nanocomposite films would exhibit a larger photonic efficiency and a longer lasting life. For the organic solar cells made from $\mathrm{MEH}-\mathrm{PPV}+\mathrm{nc}-\mathrm{TiO}{ }_{2}$ composite, a fill factor reached a value of about 0.34 . Under illumination by light with a power density of $50 \mathrm{~mW} / \mathrm{cm}^{2}$, the photoelectrical conversion efficiency was about $0.15 \%$ corresponding to an open circuit voltage $V_{\mathrm{oc}}=0.126 \mathrm{~V}$ and a shortcut circuit current density $J_{\mathrm{sc}}=1.18 \mathrm{~mA} / \mathrm{cm}^{2}$.
\end{abstract}

\section{Introduction}

Over two recent decades, conducting polymers and polymerbased devices have been increasingly studied, because of their potential application in optoelectronics as organic light emitting diodes (OLEDs), field emission transistors (FETs), solar flexible cells, and so forth [1]. From the point of energy bandgap, semiconducting polymers also have a gap (between the highest occupied molecular orbital-HOMOand the lowest unoccupied molecular orbital-LUMO-). When sufficient energy is applied to a conducting polymer, it becomes conducting by exciting the electrons from the HOMO level into the LUMO level. This excitation process leaves holes in the valence band, and thus creates "electronhole-pairs" (EHPs). When these EHPs are in intimate contact (i.e., the electrons and holes have not dissociated) they are termed "excitons." In presence of an external electric field, the electron and the hole will migrate (in opposite directions) in the conduction and valence bands, respectively (Figure 1).

On the other hand, inorganic semiconductors when reduced to the nanometer regime, possess characteristics between the classic bulk and molecular descriptions, exhibiting properties of quantum confinement. These materials are referred as nanoparticles (or nanocrystals). Thus, adding metallic, semiconducting, and dielectric nanocrystals into polymer matrices enhances the efficiency and service duration of these devices. The inorganic additives usually have nanoparticle form. Inorganic nanoparticles can substantially influence the mechanical [2-4], electrical, and optical (including nonlinear optical as well as photoluminescent, electroluminescent, and photoconductive) properties of the polymer in which they are embedded [5-8]. The influence of nanocrystalline oxides on the properties of conducting polymers has been investigated by many scientific groups [911]. Many publications have been focused on nanostructured composites, nanohybrid layers, and heterojunctions, which can be utilized for different practical purposes. Among these applications, one can divide two objectives; one focused on the interaction between electrons and photons in devices such as OLEDs, where the electricity generates light and the other aiming and the generation of electricity as in organic solar cells (OSCs). 


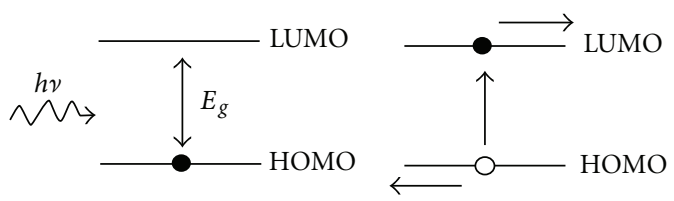

FIgURE 1: Formation of "electron-hole pair" induced by an excitation from an external energy source.

In this work we present our recent results on the morphology and properties of nanostructured polymeric composites (further called nanocomposites) made from a conjugate polymer of Poly [2-methoxy-5-(2'-ethyl-hexyloxy)-1,4phenylene vinylene] (MEH-PPV), Polyethylenedioxythiophene (PEDOT), and nanoparticles of $\mathrm{TiO}_{2}$ with the aim to use for OLEDs and OSCs.

\section{Experimental}

Sol-gel method was used to prepare nanoparticles of $\mathrm{TiO}_{2}$ with modified surface. The catalyst was trimethylamino-Noxide dihydrate $\left[\left(\mathrm{CH}_{3}\right)_{3} \mathrm{NO} \cdot 2 \mathrm{H}_{2} \mathrm{O}\right]$ with oleic acid as the derivative chemical agent. The precursor for the sol was a solution of tetraiso-propyl orthotitanate [ $\mathrm{Ti}\left(\text { iso- }-\mathrm{OC}_{3} \mathrm{H}_{7}\right)_{4}$ ]. This mixture was stirred at $80^{\circ} \mathrm{C}$ for up to 2 hours, when a homogeneous clear orange color was obtained. The optimal volume ratio of oleic acid per the precursor was found to be of $r=10$. The nanocrystalline $\mathrm{TiO}_{2}\left(\right.$ nc- $\left.-\mathrm{TiO}_{2}\right)$ powder with an average size of ca. $7 \mathrm{~nm}$ was obtained by pouring the solution onto silicon substrates followed by annealing at $180^{\circ} \mathrm{C}$, in air, for 3 hours. Annealing at such a low temperature one can avoid growing process of $\mathrm{TiO}_{2}$ particles, thus the size of the particles can be maintained at the same size of the dispersed $\mathrm{TiO}_{2}$. The detail preparation and characterization of the surface-modified $\mathrm{TiO}_{2}$ nanoparticles can be seen elsewhere [12]. These $n c-\mathrm{TiO}_{2}$ particles were used for making nanocomposites films for both the OLEDs and OSCs.

To deposit nanocomposite films, MEH-PPV was dissolved in xylene ( $8 \mathrm{mg}$ of MEH-PPV in $10 \mathrm{~mL}$ of xylene). $\mathrm{TiO}_{2}$ was then embedded in PEDOT-PSS (PEDOT+nc$\mathrm{TiO}_{2}$ ) with $15 \mathrm{wt} \%$ of $\mathrm{TiO}_{2}$ and in MEH-PPV with $20 \mathrm{wt} \%$ of $\mathrm{TiO}_{2}\left(\mathrm{MEH}-\mathrm{PPV}+\mathrm{nc}-\mathrm{TiO}_{2}\right)$. These concentrations were taken from the optimal values of the $\mathrm{TiO}_{2}$ embedded within these polymers, which were obtained and reported elsewhere [13], where commercial $\mathrm{TiO}_{2}$ nanoparticles with $5 \mathrm{~nm}$ in size were utilized. Using dispersed $n c-\mathrm{TiO}_{2}$ particles with modified surfaces, the heterojunctions created on $\mathrm{TiO}_{2}$, and polymers interfaces can be improve, consequently enhancing the energy and charge transport through these heterojunctions. Both the ultrasonic and magnetic stirring at temperature of $45^{\circ} \mathrm{C}$ was used to achieve a homogenous distribution of $\mathrm{TiO}_{2}$ within these polymers The $\mathrm{PEDOT}+\mathrm{nc}^{-\mathrm{TiO}_{2}}$ and $\mathrm{MEH}-$ $\mathrm{PPV}+\mathrm{nc}-\mathrm{TiO}_{2}$ were deposited onto ITO/glass substrates by spin-coating, then heated at $120^{\circ} \mathrm{C}$ in a vacuum of $1.33 \mathrm{~Pa}$ for 1 hour to bake out solvent. The thickness of the polymer layers was controlled by spinning rate. Each ITO/glass substrate slide consists of four devices, which have dimensions of $2 \mathrm{~mm} \times 2 \mathrm{~mm}$ or $4 \mathrm{~mm}^{2}$ in area. The process for preparing OSCs was carried-out similarly. However, in the OSC, a RF-sputtered $\mathrm{TiO}_{2}$ thin layer was added between the ITO substrate and MEH-PPV+nc-TiO 2 film, instead of the HTL (i.e., PEDOT+nc- $\mathrm{TiO}_{2}$ ) layer. The schemata of an OLED and an OSC are given in Figure 2.

\section{Results and Discussion}

3.1. Composites for OLEDs. In comparison with polyvinyl carbazone (PVK), PEDOT is a semiconducting polymer that is more suitable for the hole transport layer (HTL) in OLEDs. This is due to high transmission in the visible region, good thermal stability, and high conductivity $[14,15]$. To enhance the interface contact between ITO and PEDOT, nc-TiO nanoparticles were embedded into PEDOT [16].

Figure 3 shows the atomic force microscope (AFM) image of a PEDOT composite with a percentage of $20 \mathrm{wt} \%$ $\mathrm{TiO}_{2}$ nanoparticles ( $7 \mathrm{~nm}$ in size). With such a high resolution of the AFM one can see a distribution of nanoparticles in the polymer due to the spin-coating process. For the pure polymeric PEDOT, the surface exhibits smoothness comparable to the one of the area surrounding the nanoparticles. It is clear that $\mathrm{TiO}_{2}$ nanoparticles embedded in PEDOT created numerous $\mathrm{TiO}_{2} /$ polymer heterojunctions in the composite films.

PEDOT has a good conductivity, the electrical conductivity of this semiconducting polymer blend reaches up to $80 \mathrm{~S} / \mathrm{cm}$ [17]. As reported in [13], the conductivities of both the pure PEDOT and composite $\left(\mathrm{PEDOT}+\mathrm{nc}-\mathrm{TiO}_{2}\right)$ films measured by a four-probe method were found to be of $75 \mathrm{~S} / \mathrm{cm}$ and $70 \mathrm{~S} / \mathrm{cm}$, respectively. The presence of $\mathrm{TiO}_{2}$ nanoparticles produced a negligible decrease in film conductivity that does not affect the performance of OLEDs much when the composite was used as a hole transport layer.

Surfaces of a pure MEH-PPV and a MEH-PPV+nc$\mathrm{TiO}_{2}$ composites used for OLEDs were examined by SEM (Figure 4). The pure MEH-PPV film exhibits smooth surface, however, there are many observed cracked spots in the nanoscale. Whereas, for the composite film, with $\mathrm{TiO}_{2}$ nanoparticles embedded, these spots disappeared. Figure 4(b) presents the FE-SEM image of a composite sample with embedding of $15 \mathrm{wt} \%$ nanocrystalline titanium oxide particles with the same size (i.e., $7 \mathrm{~nm}$ ). The surface of this sample appears much smoother than the one of composites with a larger percentage of $\mathrm{TiO}_{2}$ particles or with larger size $\mathrm{TiO}_{2}$ particles.

The influence of the heat treatment on the morphology of the films was weak, that is, no noticeable differences in the surface were observed in samples annealed at $120^{\circ} \mathrm{C}$, $150^{\circ} \mathrm{C}$, or $180^{\circ} \mathrm{C}$ in the same vacuum. But the most suitable heating temperature for other properties such as the currentvoltage $(I-V)$ characteristics and the PL spectra was found to be $150^{\circ} \mathrm{C}$. In the sample considered, the distribution of $\mathrm{TiO}_{2}$ nanoparticles is mostly uniform, except for a few bright points indicating the presence of nanoparticle clusters.

The effect of nanoparticles in composite films used for both the hole transport layer (HTL) and emitting layer (EL) in OLEDs was revealed by measuring $I-V$ characteristics 


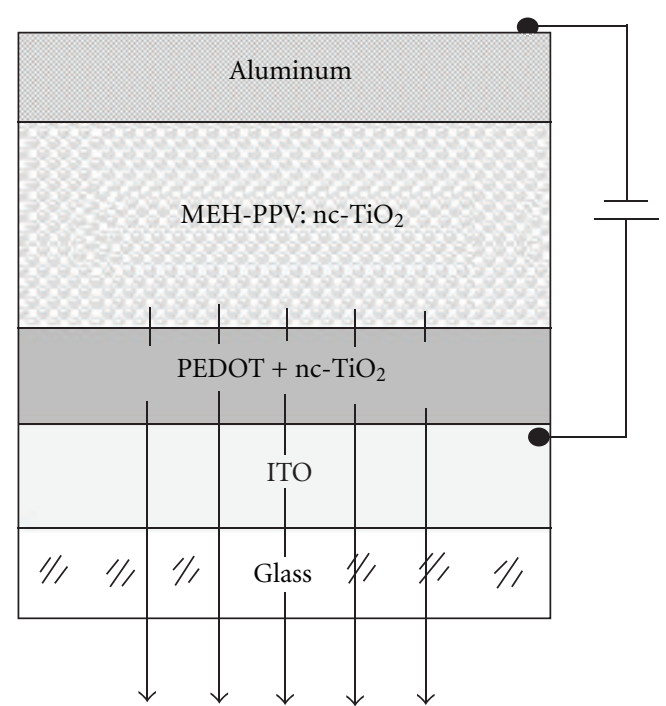

(a)

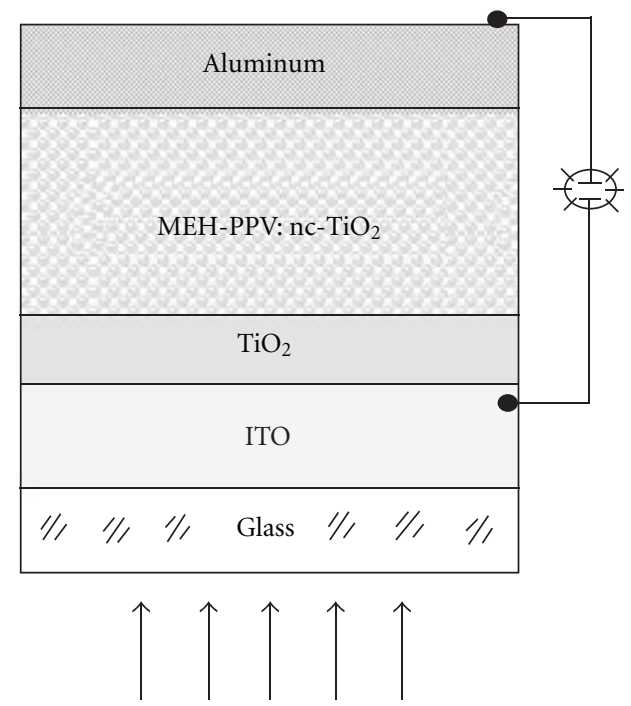

(b)

Figure 2: Schematic drawings of an OLED (a) and OSC (b): thickness of the ITO electrode is $200 \mathrm{~nm}$, the PEDOT $+\mathrm{nc}-\mathrm{TiO}_{2}$ layer $-100 \mathrm{~nm}$, the $\mathrm{MEH}-\mathrm{PPV}+\mathrm{nc}-\mathrm{TiO}_{2}$ layer $-200 \mathrm{~nm}$, for OLED and $300 \mathrm{~nm}$ for OSC, the thin $\mathrm{TiO}_{2}$ layer $-30 \mathrm{~nm}$, and the $\mathrm{Al}$ electrode $-100 \mathrm{~nm}$.

of the devices made from different layers. The following abbreviations for the devices were used:

D1: ITO/MEH-PPV/Al (single polymer EL layer),

D2: ITO/PEDOT/MEH-PPV/Al (double polymer layers),

D3: $\mathrm{ITO} / \mathrm{PEDOT}+\mathrm{TiO}_{2} / \mathrm{MEH}-\mathrm{PPV}+\mathrm{TiO}_{2} / \mathrm{Al}$ (double composite layers),

D4: ITO/PEDOT $+\mathrm{TiO}_{2} / \mathrm{MEH}-\mathrm{PPV}+\mathrm{TiO}_{2} / \mathrm{LiF} / \mathrm{Al}$ (multilayers device).

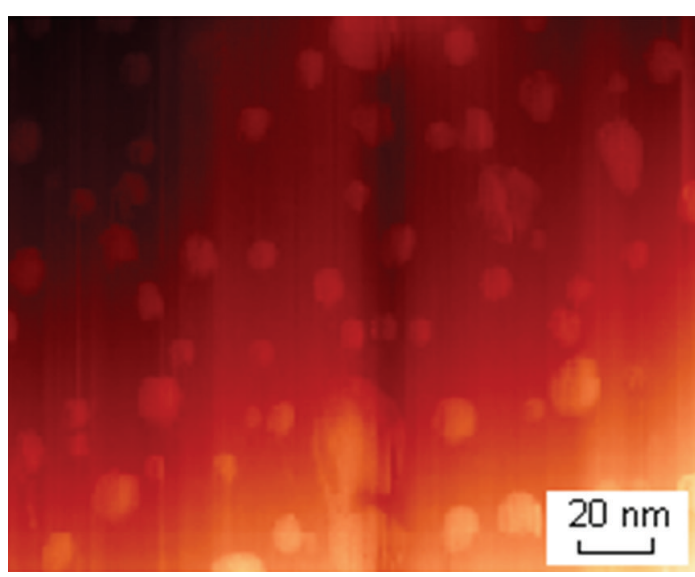

FIgure 3: AFM of a $\mathrm{PEDOT}+\mathrm{nc}-\mathrm{TiO}_{2}$ composite film with embedding of $20 \mathrm{wt} \% \mathrm{TiO}_{2}$ nanoparticles.

For the last device (D4), a super thin LiF layer as ETL was added. A $10 \mathrm{~nm}$-thick LiF layer used for the shallow contact layer (SCL) was made by electron beam deposition [13]. I-V plots of these devices are shown in Figure 5.

From Figure 5 one can see that the effect of both the HTL and ETL and/or SCL on the enhancement of the $I-V$ characteristics was well demonstrated: for a single polymer layer the turn-on voltage was of about $2.5 \mathrm{~V}$ ("a" curve in Figure 5), whereas the device with HTL ("b"), composite layers ("c") and SCL ("d" curve) the turn-on voltage decreased, from 2.5 to $2.15,2.05$, and $1.80 \mathrm{~V}$, respectively. The decrease in the turn-on voltage for the case with HTL layer is associated with the equalization process of injection rates of holes and electrons. The role of the nanoparticles affecting to the device performance can be explained as follows. In the composite film there are numerous heterojunctions formed by the polymeric matrix (either PEDOT or MEH-PPV) and nanoparticles (i.e., $\mathrm{TiO}_{2}$ ) embedded in the polymer. During spinning, the nanoparticles can adhere to the HTL by strong centrifugal forces and capillary forces can then draw the polymer solution around the nanoparticles into cavities without opening up pinholes through the device. This results in a rough surface, over which the LiF (SCL) is deposited. Subsequently, a large surface area interface between the SCL and the EL composite material is formed. At a low voltage, charge-injection into MEH-PPV is expected to be cathode limited; the very steep rise in the $I$ - $V$ curves for the composite diodes however suggests that more efficient injection at the cathode through the SCL is occurring which would be caused by the rougher interface of the nanocomposites. At a higher voltage, transport in MEH-PPV appears to be space-charge limited. Moreover, from FE-SEM (see Figure 4) it is seen that the nanoparticles made the polymeric films be free from cracked, consequently the number of the pores as the charge traps in polymers were considerably eliminated. This enables the $I-V$ characteristic of the OLEDs made from nanocomposite layers to be enhanced in comparison with the standard polymers; consequently a larger photonic efficiency can be expected. 


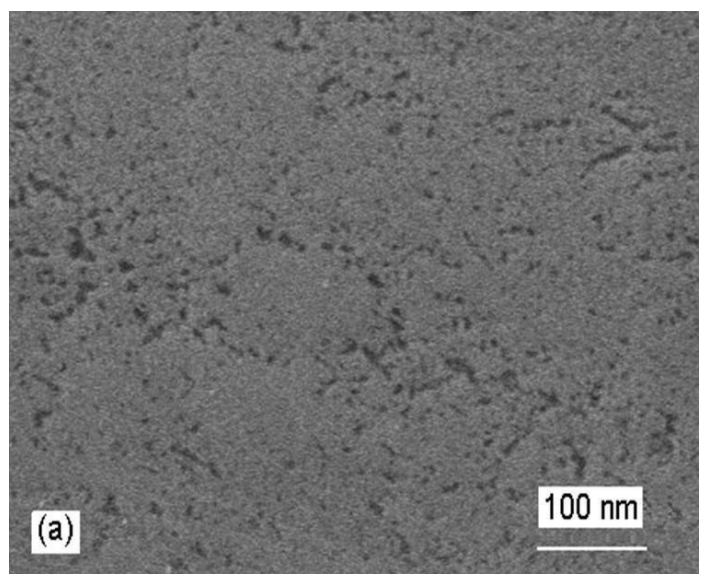

(a)

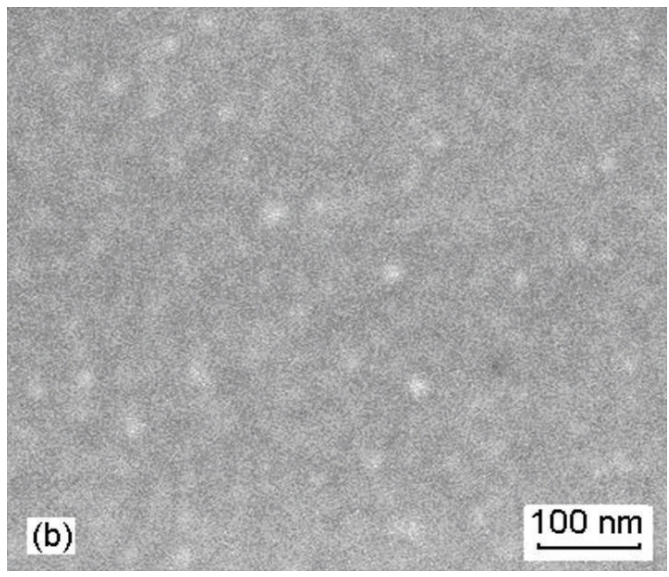

(b)

FIGURE 4: FE-SEM of a pure MEH-PPV (a) and a MEH-PPV+nc$\mathrm{TiO}_{2}\left(15 \mathrm{wt} \%\right.$ of $\left.\mathrm{TiO}_{2}\right)$ annealed in vacuum at $150^{\circ} \mathrm{C}(\mathrm{b})$.

3.2. Composites for OSCs. A MEH-PPV+nc- $\mathrm{TiO}_{2}$ film with a good quality deposited onto glass substrate from $\mathrm{MEH}$ PPV solution exhibited good film-to-substrate adhesion (Figure 6). From our experiments, it was known that the $\mathrm{TiO}_{2}$ nanoparticles became large-sized and agglomerated in the composite films as the percentage of $\mathrm{TiO}_{2}$ increases, which resulted in more highly interpenetrated networks of $\mathrm{TiO}_{2}$ produced at higher concentrations. Up to the $25 \mathrm{wt} \%$ of nc- $\mathrm{TiO}_{2}$ embedded in the MEH-PPV, the homogeneity in the distribution of $\mathrm{nc}^{-\mathrm{TiO}_{2}}$ particles in the polymer, as seen in Figure 6 is suitable for OSCs.

The absorbance spectra of the MEH-PPV films versus nc$\mathrm{TiO}_{2}$ concentration are plotted in Figure 7. From this figure one can see that nanoparticles of $\mathrm{TiO}_{2}$ made the polymer film stronger absorbing in the visible range, in wavelengths from 480 to $520 \mathrm{~nm}$ and for sample with $25 \mathrm{wt} \%$ of nc- $\mathrm{TiO}_{2}$, in particular. The fact that the absorbance of the composite films increases with the growth of $\mathrm{nc}-\mathrm{TiO}_{2}$ concentration proves that $\mathrm{TiO}_{2}$ /polymer heterojunctions within polymers are mainly responsible for the absorption of the films.

In Figure 8, the PL spectra for the MEH-PPV and the composite films with excitation wavelength of $470 \mathrm{~nm}$ are

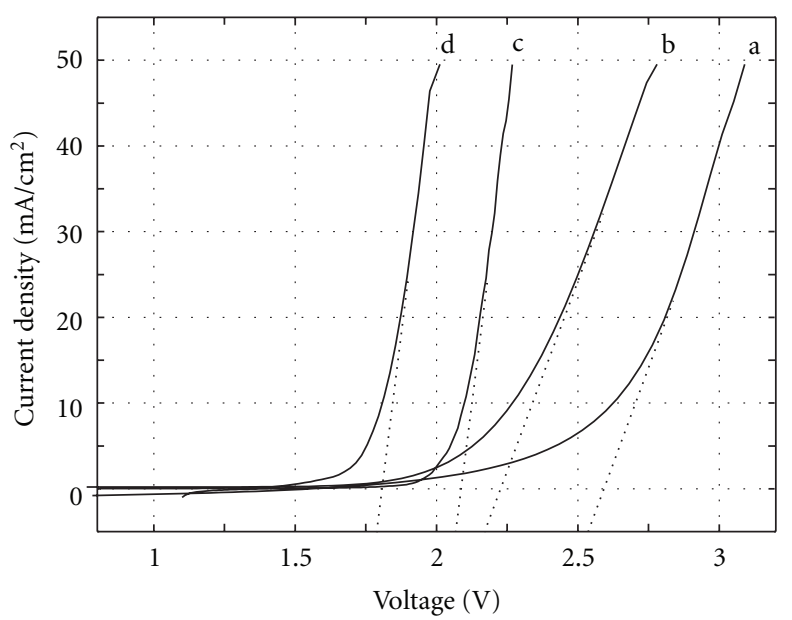

Figure 5: $I-V$ characteristics of OLED with different laminated structure. a-Single MEH-PPV (D1), b-with HTL layer (D2), c-with HTL and EL composite layers (D3), and d-with super thin LiF layer (D4).

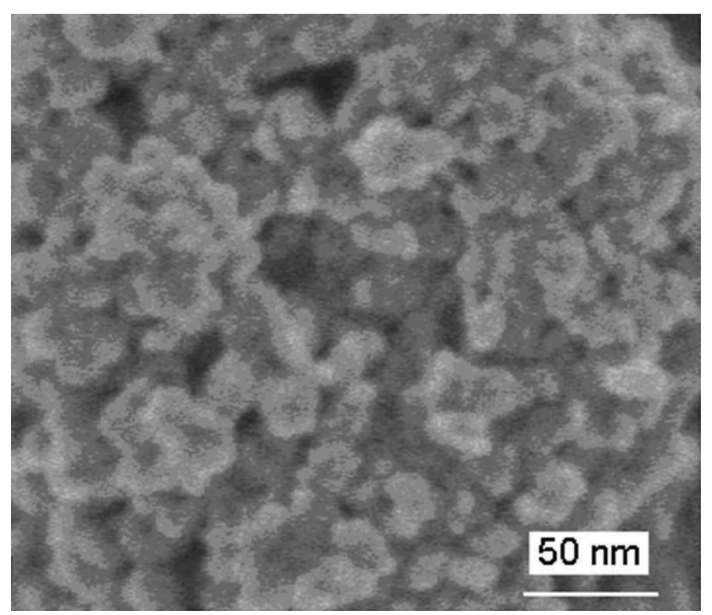

FIgure 6: FE-SEM photograph of the MEH-PPV + nc- $-\mathrm{TiO}_{2}$ nanocomposite film with $25 \mathrm{wt} \%$ of $\mathrm{nc}-\mathrm{TiO}_{2}$.

plotted. In this case, the MEH-PPV luminescence quenching was observed. For both samples, the photoemission has two broad peaks, respectively, at $580.5 \mathrm{~nm}$ and $615.3 \mathrm{~nm}$. The peak observed at $580.5 \mathrm{~nm}$ is larger than the one at $615.3 \mathrm{~nm}$, similarly to the electroluminescence spectra observed in [18]. As seen [7] for a composite, in the presence of rodlike $\mathrm{TiO}_{2}$ nanocrystals, PPV quenching of fluorescence is significantly high. This phenomenon was explained by the transfer of the photogenerated electrons to the $\mathrm{TiO}_{2}$. It is known [19] that the fluorescence quenching of MEH-PPV results in charge-separation at interfaces of $\mathrm{TiO}_{2} / \mathrm{MEH}-\mathrm{PPV}$, consequently reducing the barrier height at those interfaces. The charge-separation in the polymeric nanocomposite under the illumination is a specific property that is desired for designing a simple, but prospective organic solar cell.

A schematic draw of a multilayer OSC with use of the nanocomposite is shown in Figure 2(b). A solid-state 


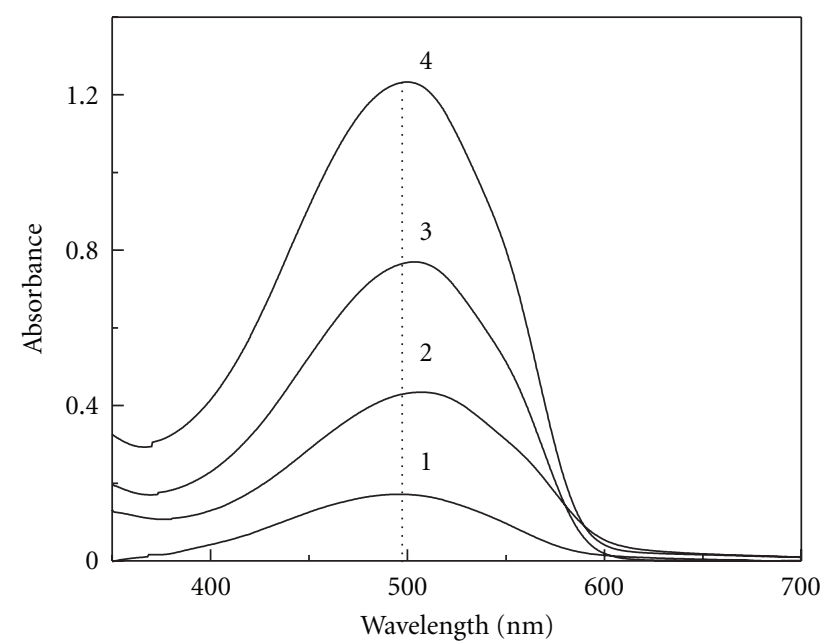

Figure 7: Absorption spectra of of $\mathrm{MEH}-\mathrm{PPV}+\mathrm{nc}-\mathrm{TiO}_{2}$ at room temperature; curves " 1 ," “ 2 ," “ 3 ," and " 4 " correspond to a pure MEH-PPV film, $5 \mathrm{wt} \%, 15 \mathrm{wt} \%$, and $25 \mathrm{wt} \%$ of nc-TiO ${ }_{2}$ embedded within MEH-PPV, respectively.

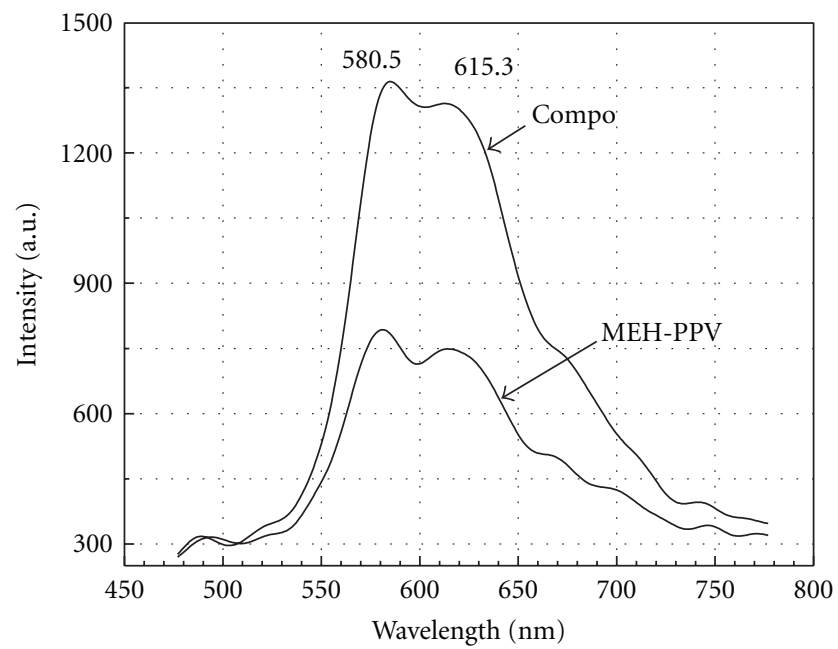

FIgURE 8: PL spectra of MEH-PPV+nc- $\mathrm{TiO}_{2}$. Excitation beam with $\lambda=470 \mathrm{~nm}$.

photovoltaic device using a surface-adsorbed dye complex for light absorption and electron injection to the $\mathrm{TiO}_{2}$ layer is called eta-solar cell, in which an extremely thin absorber (eta) is sandwiched between two wide-band gap semiconductors, one n-type and the other p-type [20-22]. The simplest device consists of two these layers, so it is called as a bilayer solar cell. In our experiments, instead of the polymer layer, a nanocomposite layer was deposited by spin coating onto the $\mathrm{TiO}_{2} / \mathrm{ITO}$ electrode. Here, $30 \mathrm{~nm}$ thick $\mathrm{TiO}_{2}$ was deposited by RF-sputtering. To prepare OSCs with structure of $\mathrm{ITO} / \mathrm{TiO}_{2} / \mathrm{MEH}-\mathrm{PPV}+\mathrm{nc}-\mathrm{TiO}_{2} / \mathrm{Al}$, a thin aluminum electrode was successively evaporated onto the composite layer (Figure 2(b)). Figure 9 shows the currentvoltage characteristics of an OSC using the nanocomposite with $25 \mathrm{wt} \%$ of nc- $\mathrm{TiO}_{2}$, the dark current is given in a dashed line.

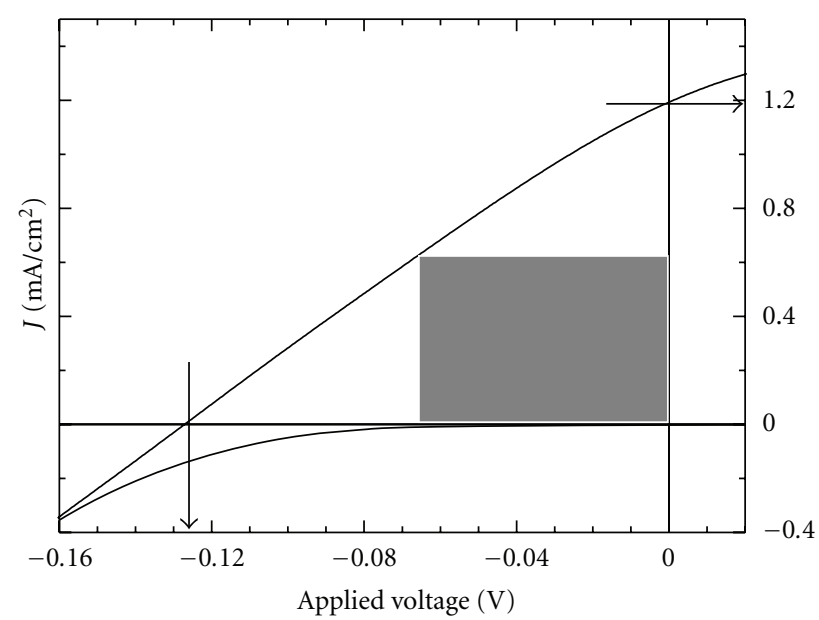

Figure 9: $I-V$ characteristics of a OSC: thickness the $\mathrm{TiO}_{2}$ layer is of $30 \mathrm{~nm}$, the nanocomposite film $-300 \mathrm{~nm}$ and the $\mathrm{Al}$ electrode $100 \mathrm{~nm} . P_{\text {in }}=50 \mathrm{~mW} / \mathrm{cm}^{2}, V_{\mathrm{oc}}=0.126 \mathrm{~V}, J_{\mathrm{sc}}=1.18 \mathrm{~mA} / \mathrm{cm}^{2}, \mathrm{FF}=$ 0.34 , and $\mathrm{PEC}=0.15 \%$.

The photoelectrical conversion efficiency (PEC) was determined by using the following formula:

$$
\mathrm{PEC}=\frac{\mathrm{FF} \times J_{\mathrm{sc}} \times V_{\mathrm{oc}}}{P_{\text {in }}},
$$

where $P_{\text {in }}$ is the density illumination power and FF is the fill factor equal to:

$$
\mathrm{FF}=\frac{(J \times V) \max }{J_{\mathrm{sc}} \times V_{\mathrm{oc}}} .
$$

$V_{\text {oc }}$-voltage in open circuit, $J_{\text {sc }}$-current of short circuit.

The gray-colour rectangle illustrates the fill factor that is equal to 0.34 determined by formula (2). The fact that the FF is considerably large proves that the nanostructured composite is a good matrix where $\mathrm{TiO}_{2}$ particles are tightly surrounded. This is because during the spinning process in the spin-coating technique, the nanoparticles can adhere by strong electrostatic forces to the polymer and between themselves, and capillary forces can then draw the MEHPPV solution around the nanoparticles into cavities without opening up pinholes through the device. Although the thickness of the nanocomposite layer is small $(300 \mathrm{~nm})$, using formula (1) the PEC of the multilayer OSCs with the structure of $\mathrm{Al} / \mathrm{MEH}-\mathrm{PPV}+\mathrm{nc}-\mathrm{TiO}_{2} / \mathrm{TiO}_{2} / \mathrm{ITO}$ was found to be of $0.15 \%$. This value is small in comparison with solid-state $\mathrm{PbS}-\mathrm{QDs} / \mathrm{TiO}_{2}(500 \mathrm{~nm})$ heterojunction solar cells which have a PEC of $3.5 \%$ under AM1.5 illumination [23]. However, it can be comparable to the PEC of the polymer/nanocomposite solar cell that was obtained after an annealing treatment under the electrical field of $4 \mathrm{~V} \mathrm{[24].}$

\section{Conclusion}

$\mathrm{Nc}-\mathrm{TiO}_{2}$ particles with modified-surfaces were synthesized by the sol-gel method using oleic acid. Nanocomposite films for a HTL and EL were prepared, respectively, from PEDOT 
and MEH-PPV incorporated with these nanoparticles. Study of the electrical and photoluminescent properties of the composites as well as $I-V$ characteristics of the OLEDs based on the composites showed that electrical and spectroscopic properties of the conjugate polymers were enhanced due to the incorporation of $n c-\mathrm{TiO}_{2}$ in the polymers. The OLEDs made from the nanocomposite films would exhibit a larger photonic efficiency and a longer lasting life.

The same nanocomposite (i.e., $\mathrm{MEH}-\mathrm{PPV}+\mathrm{nc}-\mathrm{TiO}_{2}$ ) was used for OSCs. The fill factor of such an OSC was reached a value as high as 0.34 . Under illumination of light with a power density of $50 \mathrm{~mW} / \mathrm{cm}^{2}$, the following parameters of the cell were obtained: $V_{\mathrm{oc}}=0.126 \mathrm{~V}, J_{\mathrm{sc}}=1.18 \mathrm{~mA} / \mathrm{cm} 2, \mathrm{FF}=$ 0.34 , and PEC $=0.15 \%$.

\section{Acknowledgment}

This work was supported in part by MOST of Vietnam through the Project on Fundamental Scientific Research and Applications, code 1/2010/HD-DTNCCBUD.

\section{References}

[1] B. D. Malhotra, Handbook of Polymers in Electronics, Rapra Technology, Shawbury, UK, 2002.

[2] T. P. Selvin, J. Kuruvilla, and T. Sabu, "Mechanical properties of titanium dioxide-filled polystyrene microcomposites," Materials Letters, vol. 58, no. 3-4, pp. 281-289, 2004.

[3] J. Móczó and B. Pukánszky, "Polymer micro and nanocomposites: structure, interactions, properties," Journal of Industrial and Engineering Chemistry, vol. 14, no. 5, pp. 535-563, 2008.

[4] S. A. Choulis, M. K. Mathai, and V. E. Choong, "Influence of metallic nanoparticles on the performance of organic electrophosphorescence devices," Applied Physics Letters, vol. 88, no. 21, Article ID 213503, 3 pages, 2006.

[5] J. S. Salafsky, "Exciton dissociation, charge transport, and recombination in ultrathin, conjugated polymer- $\mathrm{TiO}_{2}$ nanocrystal intermixed composites," Physical Review B, vol. 59, no. 16, pp. 10885-10894, 1999.

[6] W. U. Huynh, J. J. Dittmer, and A. P. Alivisatos, "Hybrid nanorod-polymer solar cells," Science, vol. 295, no. 5564, pp. 2425-2427, 2002.

[7] A. Petrella, M. Tamborra, P. D. Cozzoli et al., " $\mathrm{TiO}_{2}$ nanocrystals-MEH-PPV composite thin films as photoactive material," Thin Solid Films, vol. 451-452, pp. 64-68, 2004.

[8] V. M. Burlakov, K. Kawata, H. E. Assender, G. A. D. Briggs, A. Ruseckas, and I. D. W. Samuel, "Discrete hopping model of exciton transport in disordered media," Physical Review B, vol. 72, no. 7, Article ID 075206, pp. 1-5, 2005.

[9] D. E. Markov and P. W. M. Blom, "Migration-assisted energy transfers at conjugated polymer/metal interfaces," Physical Review B, vol. 72, pp. 161401R-161404R, 2005.

[10] K. Kawata, V. M. Burlakov, M. J. Carey et al., "Description of exciton transport in a $\mathrm{TiO}_{2} / \mathrm{MEH}-\mathrm{PPV}$ heterojunction photovoltaic material," Solar Energy Materials and Solar Cells, vol. 87, no. 1-4, pp. 715-724, 2005.

[11] S. A. Choulis, M. K. Mathai, and V. E. Choong, "Influence of metallic nanoparticles on the performance of organic electrophosphorescence devices," Applied Physics Letters, vol. 88, no. 21, Article ID 213503, 2006.
[12] D. N. Chung, N. N. Dinh, D. Hui, N. D. Duc, T. Q. Trung, and M. Chipara, "Investigation of polymeric composite films using modified $\mathrm{TiO}_{2}$ nanoparticles for organic emitting diodes," Current Nanoscience Journal. In press.

[13] T. T. C. Thuy, Preparation of nanostructured composites for Organic Light Emitting Diodes and, characterization of their electrical and spectro-optic properties [Ph.D. thesis], 2010.

[14] J. Ouyang, Q. Xu, C. W. Chu, Y. Yang, G. Li, and J. Shinar, "On the mechanism of conductivity enhancement in poly $(3,4-$ ethylenedioxythiophene):poly(styrene sulfonate) film through solvent treatment," Polymer, vol. 45, no. 25, pp. 8443-8450, 2004.

[15] P. Tehrani, A. Kanciurzewska, X. Crispin, N. D. Robinson, M. Fahlman, and M. Berggren, "The effect of $\mathrm{pH}$ on the electrochemical over-oxidation in PEDOT:PSS films," Solid State Ionics, vol. 177, no. 39-40, pp. 3521-3527, 2007.

[16] N. N. Dinh, L. H. Chi, T. T. Chung Thuy, T. Q. Trung, and V. V. Truong, "Enhancement of current-voltage characteristics of multilayer organic light emitting diodes by using nanostructured composite films," Journal of Applied Physics, vol. 105, no. 9, Article ID 093518, 2009.

[17] J. Ouyang, Q. Xu, C. W. Chu, Y. Yang, G. Li, and J. Shinar, "On the mechanism of conductivity enhancement in poly $(3,4-$ ethylenedioxythiophene):poly(styrene sulfonate) film through solvent treatment," Polymer, vol. 45, no. 25, pp. 8443-8450, 2004.

[18] S. A. Carter, J. C. Scott, and P. J. Brock, "Enhanced luminance in polymer composite light emitting devices," Applied Physics Letters, vol. 71, no. 9, pp. 1145-1147, 1997.

[19] S. H. Yang, T. P. Nguyen, P. Le Rendu, and C. S. Hsu, "Optical and electrical properties of $\mathrm{PPV} / \mathrm{SiO}_{2}$ and $\mathrm{PPV} / \mathrm{TiO}_{2}$ composite materials," Composites Part A, vol. 36, no. 4, pp. 509-513, 2005.

[20] K. Tennakone, G. R. R. A. Kumara, I. R. M. Kottegoda, V. P. S. Perera, and G. M. L. P. Aponsu, "Nanoporous n$\mathrm{TiO}_{2}$ /selenium/p-CuCNS photovoltaic cell," Journal of Physics $D$, vol. 31, no. 18, pp. 2326-2330, 1998.

[21] I. Kaiser, K. Ernst, C. H. Fischer et al., "Eta-solar cell with $\mathrm{CuInS}_{2}$ : a photovoltaic cell concept using an extremely thin absorber (eta)," Solar Energy Materials and Solar Cells, vol. 67, no. 1-4, pp. 89-96, 2001.

[22] B. O'Regan, F. Lenzmann, R. Muis, and J. Wienke, "A solidstate dye-sensitized solar cell fabricated with pressure-treated $\mathrm{P} 25-\mathrm{TiO}_{2}$ and $\mathrm{CuSCN}$ : analysis of pore filling and IV characteristics," Chemistry of Materials, vol. 14, no. 12, pp. 50235029, 2002.

[23] L. Etgar, T. Moehl, S. Gabriel, S. G. Hickey, A. Eychmüller, and M. Grätzel, "Light energy conversion by mesoscopic PbS quantum dots $/ \mathrm{TiO}_{2}$ Heterojunction Solar Cells," ACS Nano, vol. 6, no. 4, pp. 3092-3099, 2012.

[24] A. K. Pandey, J. M. Nunzi, H. Wang et al., "Reverse biased annealing: effective post treatment tool for polymer/nanocomposite solar cells," Organic Electronics: Physics, Materials, Applications, vol. 8, no. 4, pp. 396-400, 2007. 

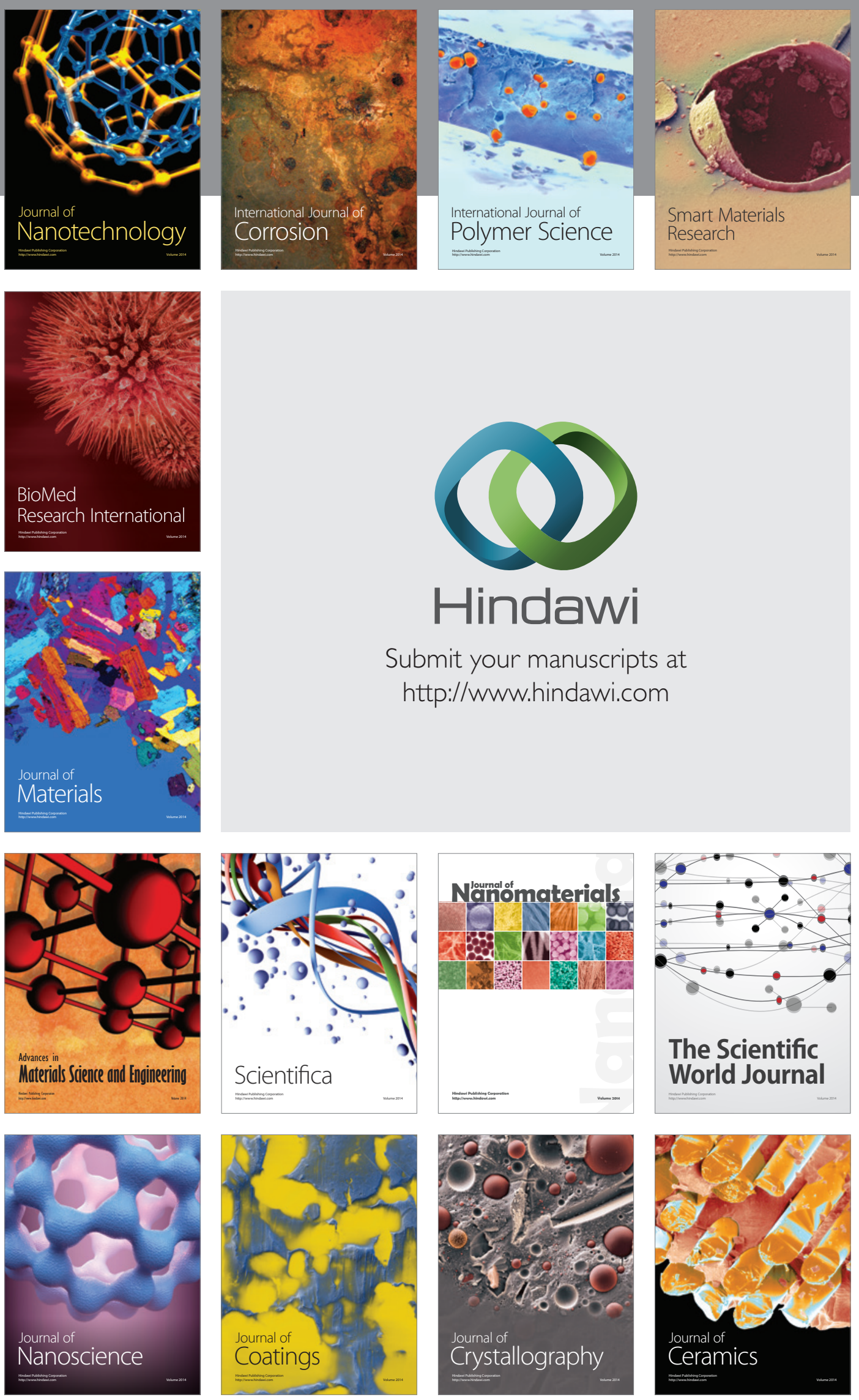

The Scientific World Journal

Submit your manuscripts at

http://www.hindawi.com

\section{World Journal}

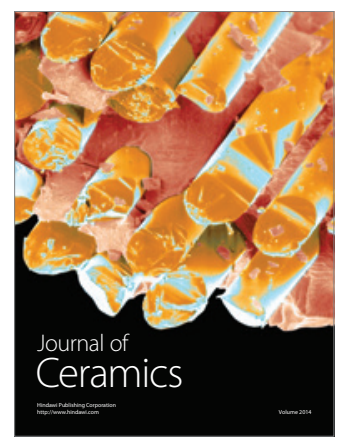

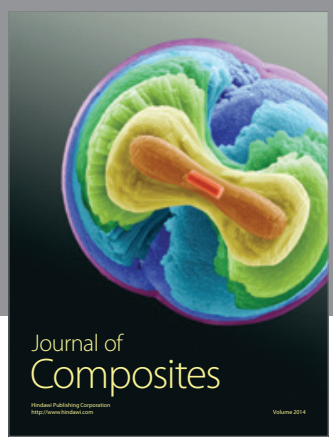
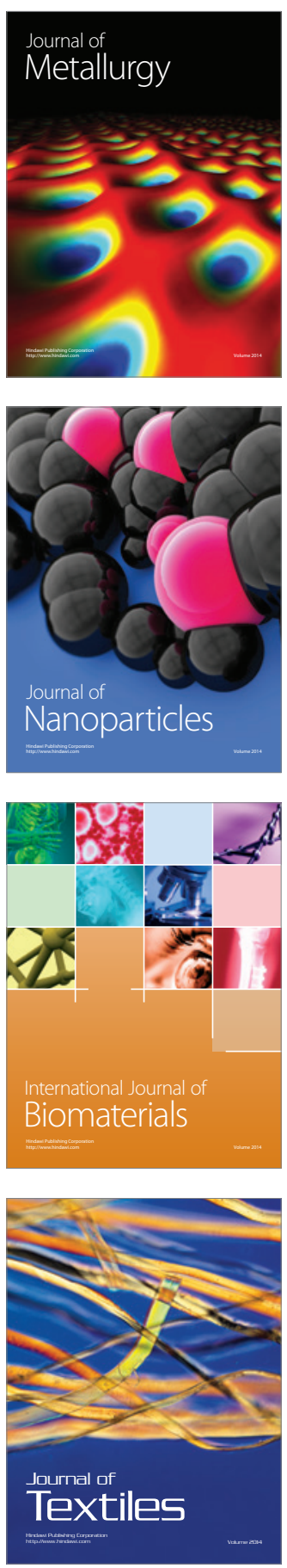